\title{
Echocardiographic assessment of severity of aortic regurgitation
}

\author{
K. E. Gray ${ }^{1}$ and D. W. Barritt \\ From the Cardiac Department, Bristol General Hospital, Guinea Street, Bristol
}

An echocardiographic study of left ventricular diameter was made in 27 patients with aortic regurgitation. Comparison was made with a group of 21 normal subjects and a group of 6 patients with large left ventricles without valvar regurgitation. Total stroke volume, total left ventricular output, and ejection fraction were derived by the method of cubing the left ventricular diameter to give approximate left ventricular volumes at end-diastole and end-systole. The patients were assessed independently and placed into three grades of severity. The echocardiographic dimensions of patients with mild aortic regurgitation were not significantly different from those of the normal subjects. With increasing severity of aortic regurgitation, there were increases in group values for left ventricular diameter, total stroke volume, and total left ventricular output. The ejection fraction was depressed below the normal range in only one patient with aortic regurgitation.

It is concluded that echocardiographic measurement of left ventricular dimensions is of value in assessing the severity of aortic regurgitation.

In many patients it is difficult to assess accurately the severity of aortic regurgitation by clinical and non-invasive radiological methods. Cine-aortography offers a method of classification of the severity of regurgitation into one of three or four grades (Cohn et al., 1967), but this requires arterial catheterization which limits how often the study may be repeated. More detailed information may be gained by quantitative angiography (Miller, Kirklin, and Swan, 1965), but this is also invasive and the calculations involved are time consuming.

It has been demonstrated that the diameter of the left ventricle and shortening of that diameter with systole may be measured by echocardiography (Feigenbaum, Zaky, and Nasser, 1967; Chapelle and Mensch, 1969). An estimate of left ventricular volume may be obtained by cubing this diameter, and approximate values for stroke volume and ejection fraction may be obtained from measurements at end-diastole and end-systole (Pombo, Troy, and Russell, I97I; Gibson, 1973; ten Cate et al., 1974). When stroke volume is derived by this means in patients with valvar regurgitation the total stroke volume is estimated, being the sum of the forward stroke volume and the regurgitant fraction. Popp

Received 30 January 1975.

${ }^{1}$ Present address: Barnet General Hospital, Wellhouse Lane, Barnet, Herts EN5 3DJ. and Harrison (I970) estimated the regurgitant fraction in patients with mitral regurgitation and patients with aortic regurgitation by subtracting the forward stroke volume measured by the Fick technique from the stroke volume measured by echocardiography. Danford et al. (1973) estimated aortic regurgitant flow in 12 patients with mild or moderate aortic regurgitation by subtracting the mitral valve flow from the aortic valve flow, having estimated the mitral valve flow from the opening velocity of the anterior cusp.

In the present study the left ventricular diameter was measured by echocardiography and the total stroke volume estimated in patients with aortic regurgitation of varying degrees of severity. The results were compared with an independent assessment of the severity by clinical and radiological methods.

\section{Patients and methods}

Echocardiographic studies were made in three groups of subjects.

\section{Patients with aortic regurgitation}

Technically satisfactory recordings were obtained in 27 patients. Patients with mitral regurgitation or dominant aortic stenosis were excluded. Patients with left bundlebranch block were excluded as this lesion may cause 
asymmetrical left ventricular contraction and may invalidate estimates of stroke volume (McDonald, 1973). The 27 patients were all in sinus rhythm. Six of the patients (Cases 8, I2, I5, 19, 20, and 23) had relatively acute aortic regurgitation, having had subacute bacterial endocarditis in the year before study. Among the 27 patients were 5 who, at some stage of their illness, had had radiological evidence of pulmonary oedema, but in only 2 patients (Cases 18 and 19) had raised jugular venous pressure ever been noted and only in Case 19 was this raised at the time of the echocardiographic examination. Both Cases 18 and 19 had relatively acute aortic regurgitation caused by a leak of sudden onset around the seat of a Starr valve. Six of the patients (Cases 12, 15, 17, 18, 19, and 23) were referred for aortic valve replacement shortly after the echocardiographic examination. An echocardiographic study was attempted in 4 other patients with aortic regurgitation but satisfactory recordings were not obtained.

\section{Normal subjects}

Twenty-one healthy subjects, mainly medical students, were studied as one control group. Their ages ranged from 20 to $29 ; 18$ were men and 3 were women.

\section{Patients with cardiomyopathy}

Echocardiographic studies were made in 6 subjects who had large left ventricles but no evidence of valvar regurgitation, as a second control group. The diagnosis in these subjects was congestive cardiomyopathy and all had had evidence of left ventricular failure. Patients with clinical or electrocardiographic evidence of coronary artery disease were excluded as the left ventricles of such patients may show asymmetrical contraction. Five of these patients were in sinus rhythm and one was in atrial fibrillation.

Subjects were studied supine or lying inclined to the left and echocardiographic recordings were obtained with an Ekoline 20 ultrasonoscope ${ }^{1}$ using a $2.25 \mathrm{MHz}$ $1.5 \mathrm{~cm}$ transducer, with a pulse repetition frequency of $1000 / \mathrm{s}$. The transducer was positioned at the left sternal edge and angled to identify the mitral valve echo and then pointed more laterally and inferiorly until the left side of the interventricular septum and the endocardium of the posterior wall of the left ventricle could be clearly identified. During the early part of the study recordings were obtained on Polaroid film, but subsequently recordings were made on direct print recording paper using a Kent Cambridge fibre-optic strip chart recorder. ${ }^{2}$ The diastolic diameter (Dd) of the left ventricle was measured at the time of inscription of the main peak of the QRS complex of the electrocardiogram and the systolic diameter (Ds) was taken as the minimum diameter of the left ventricle following ventricular contraction (Fig. I). Total stroke volume was calculated from $\left(\mathrm{Dd}^{3}-\mathrm{Ds}^{3}\right)$ and total left ventricular output as (stroke volume $\times$ heart rate). Ejection fraction was

\footnotetext{
${ }^{1}$ Smith Kline Instrument Co. Ltd.

${ }^{2}$ Kent Cambridge Medical Ltd.
}

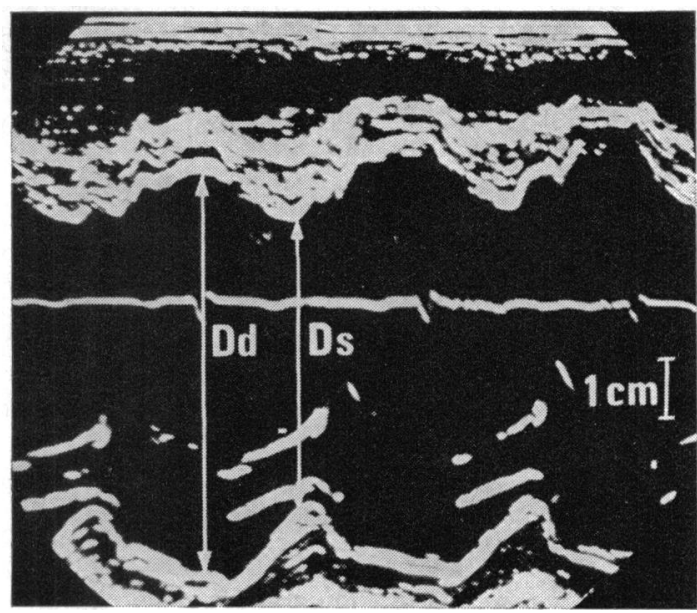

FIG. I Echocardiographic trace, recorded on Polaroid film, showing diastolic $(D d)$ and systolic $(D s)$ diameters of the left ventricle.

calculated as $\frac{\left(\mathrm{Dd}^{3}-\mathrm{Ds}^{3}\right)}{\mathrm{Dd}^{3}}$. Measurements were usually made from recordings of 2 to 4 cardiac cycles, and when measurements varied between cycles the mean was taken. In the patient with atrial fibrillation the mean of 8 cycles was taken.

\section{Reproducibility}

In 22 subjects a second echocardiographic recording was made at an interval of not less than 5 minutes after the first recording, and both first and second recordings were subsequently read 'blind', with no knowledge of the identity of the subjects.

\section{Independent assessment of severity of aortic regurgitation}

To provide a comparison with the echocardiographic data, an assessment of the severity of aortic regurgitation was made by one of us (D.W.B.) who had no knowledge of the echocardiographic findings. This assessment was based on the clinical, radiographic, and electrocardiographic findings. Particular emphasis was placed on the pulse pressure, cardiothoracic ratio on the chest radiograph, and signs of left ventricular hypertrophy on the electrocardiogram. Haemodynamic data from cardiac catheterization and cine-aortographic studies were available in 13 of the 27 patients. From this information the patients were placed in one of three grades of severity; mild (grade I), 5 patients; moderate (grade II), 6 patients; severe (grade III), I6 patients. All 6 patients who were subsequently referred for aortic valve replacement were placed in grade III.

\section{Postoperative study}

Echocardiographic studies were made postoperatively in 
3 of the patients and in 2 additional subjects, one of whom was originally excluded from the study because of left bundle-branch block and, therefore, only his left ventricular diastolic diameter was measured. The second subject became available after the original series was completed.

\section{Statistical method}

Statistical significances between group values were calculated by analysis of the variance ratio.

\section{Results}

\section{Left ventricular end-diastolic diameter}

The range in the normal subjects was 4.2 to $5.8 \mathrm{~cm}$ (Table $\mathrm{I}$ ). In the patients with aortic regurgitation the range was 4.0 to $9.1 \mathrm{~cm}$ (Table 2). Patients of grade I severity (Fig. 2) had diameters within the normal range. With grade II severity the range was 5.4 to $7.1 \mathrm{~cm}$ and with grade III severity the range was 5.7 to $9.1 \mathrm{~cm}$. The 2 patients with severe regurgitation and left ventricular diameters of $5.7 \mathrm{~cm}$ and $5.9 \mathrm{~cm}$ both had relatively acute aortic regurgitation caused by subacute bacterial endocarditis during the 2 months before study.

The differences between values for grade I and grade II patients were significantly different at the 5 per cent level and between grade II and grade III patients at the I per cent level.

\section{Total stroke volume}

The results for the three groups of subjects are displayed in Fig. 3. In the normal subjects the stroke volume was 46 to $158 \mathrm{ml}$. None of the 6 patients with cardiomyopathy and left ventricular failure had a stroke volume above the normal range, but the patients with aortic regurgitation had total stroke volumes of 43 to $465 \mathrm{ml}$. The range in patients with grade I severity (Fig. 4) was 43 to I07 ml, grade II 89 to $229 \mathrm{ml}$, and grade III I4I to $465 \mathrm{ml}$. The values for grade I were significantly different from those of grade II at the 5 per cent level and grade II differed significantly from grade III at the I per cent level.

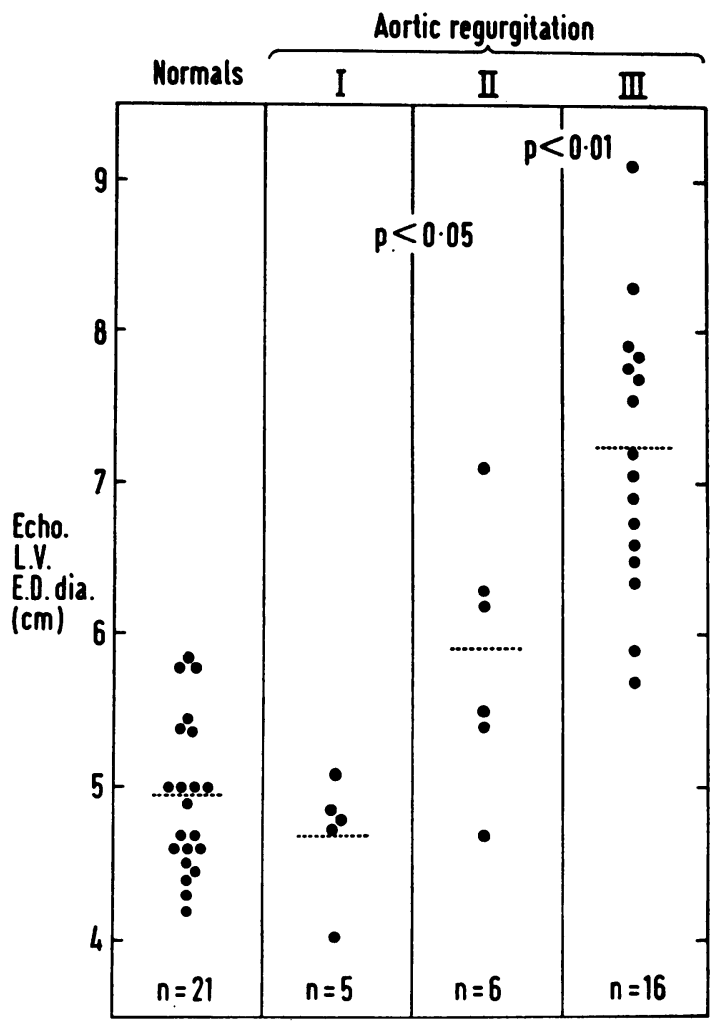

FIG. 2 Left ventricular end-diastolic diameter in the normal subjects and in the three grades of severity of aortic regurgitation.

\section{Total left ventricular output}

The range in normal subjects was 3.1 to $8.51 / \mathrm{min}$. In 4 of the 6 patients with cardiomyopathy (Table 3) the left ventricular output was within the normal range, while in 2 the values were raised to $8.91 / \mathrm{min}$ and $12.6 \mathrm{l} / \mathrm{min}$. The patients with aortic regurgitation showed values for left ventricular output of 3.5 to $37.7 \mathrm{l} / \mathrm{min}$. In grade I (Fig. 5) values were

TABLE I Summary of echocardiographic findings in 21 normal subjects

\begin{tabular}{|c|c|c|c|c|c|c|c|c|c|c|c|}
\hline \multicolumn{2}{|c|}{$\begin{array}{l}\text { LV diastolic } \\
\text { diameter }(\mathrm{cm})\end{array}$} & \multicolumn{2}{|c|}{$\begin{array}{l}L V \text { systolic } \\
\text { diameter }(\mathrm{cm})\end{array}$} & \multicolumn{2}{|c|}{$\begin{array}{l}\text { Total stroke } \\
\text { volume }(\mathrm{ml})\end{array}$} & \multicolumn{2}{|c|}{$\begin{array}{l}\text { Heart rate } \\
\text { (beats/min) }\end{array}$} & \multicolumn{2}{|c|}{$\begin{array}{l}\text { Total LV } \\
\text { output }(l / \min )\end{array}$} & \multicolumn{2}{|c|}{ Ejection fraction } \\
\hline Mean & Range & Mean & Range & Mean & Range & Mean & Range & Mean & Range & Mean & Range \\
\hline 4.9 & $4.2-5.8$ & $3 \cdot 3$ & $2.7-4.1$ & 86 & $46-158$ & 64 & $43-78$ & $5 \cdot 3$ & $3.1-8.5$ & 0.69 & $0.55-0.80$ \\
\hline
\end{tabular}


TABLE 2 Diagnoses and echocardiographic findings in patients with aortic regurgitation

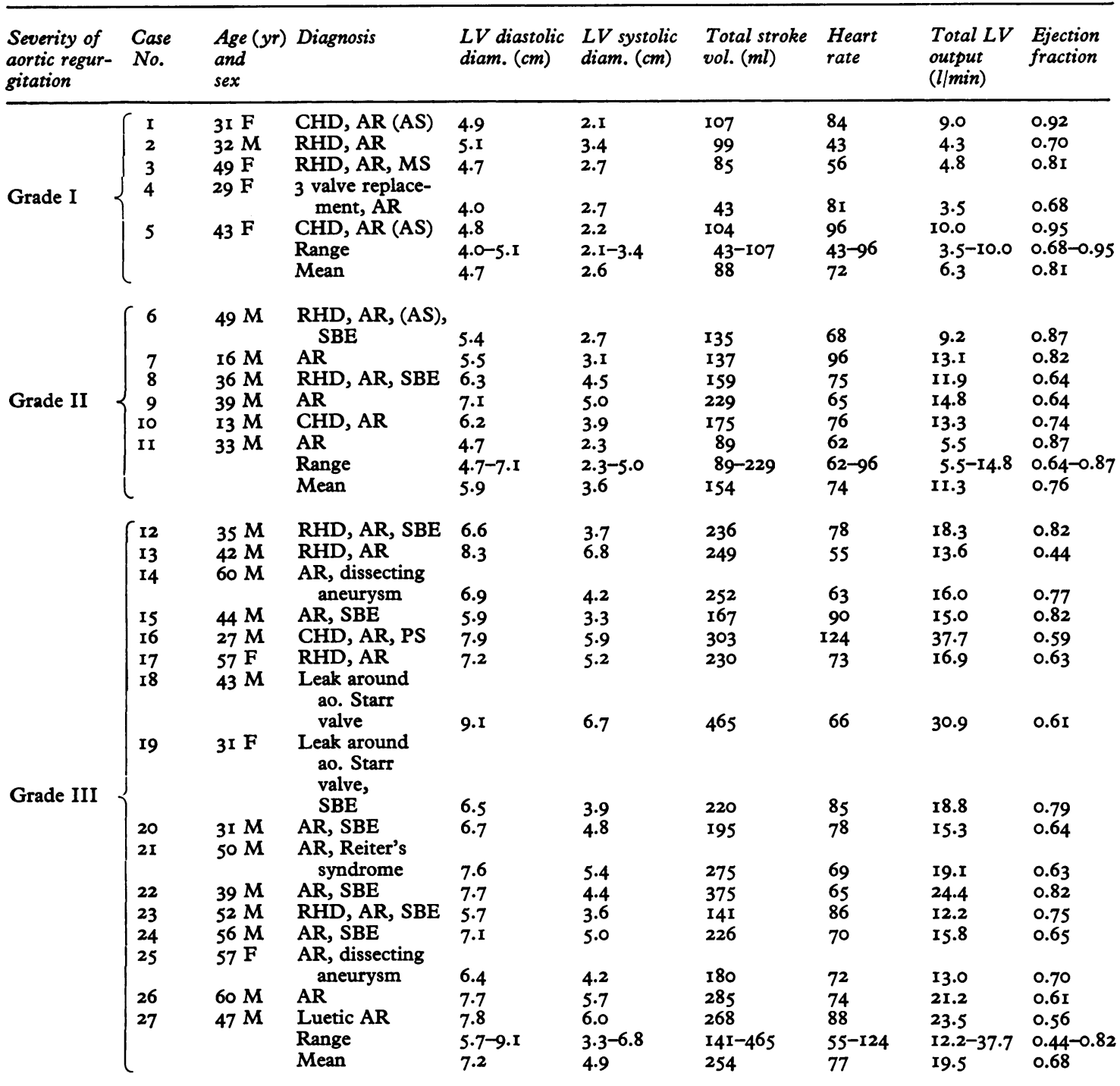

Significance ( $P$ value) of difference between the 3 grades

LV diastolic Stroke vol. LV output

Grade I cf grade II diameter

Grade II cf grade III

$\begin{array}{lll}<0.05 & <0.05 & <0.05 \\ <0.01 & <0.01 & <0.02\end{array}$

Abbreviations: RHD, rheumatic heart disease; AR, aortic regurgitation; SBE, subacute bacterial endocarditis; CHD, congenital heart disease; AS, aortic stenosis; PS, pulmonary stenosis; MS, mitral stenosis. 


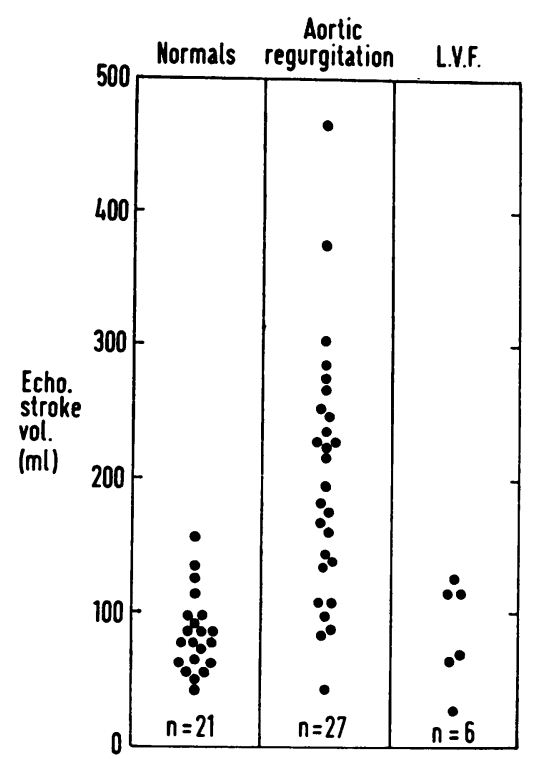

FIG. 3 Total stroke volume, estimated by echocardiography, in the three groups of subjects.

3.5 to $10.01 / \mathrm{min}$, in grade II 5.5 to $\mathrm{I} 4.8 \mathrm{l} / \mathrm{min}$, and in grade III 12.2 to $37.7 \mathrm{l} / \mathrm{min}$. Grade I differed significantly from grade II at the 5 per cent level and grade II from grade III at the 2 per cent level.

\section{Ejection fraction}

Fig. 6 shows the relation between left ventricular end-diastolic diameter and derived total stroke volume in the three groups of subjects. The line joins theoretical points having an ejection fraction of 0.5 . The patients with cardiomyopathy and left ventricular failure had inappropriately large left ventricles for stroke volumes within the normal range. They were clearly separated from those patients with aortic regurgitation who had a similar

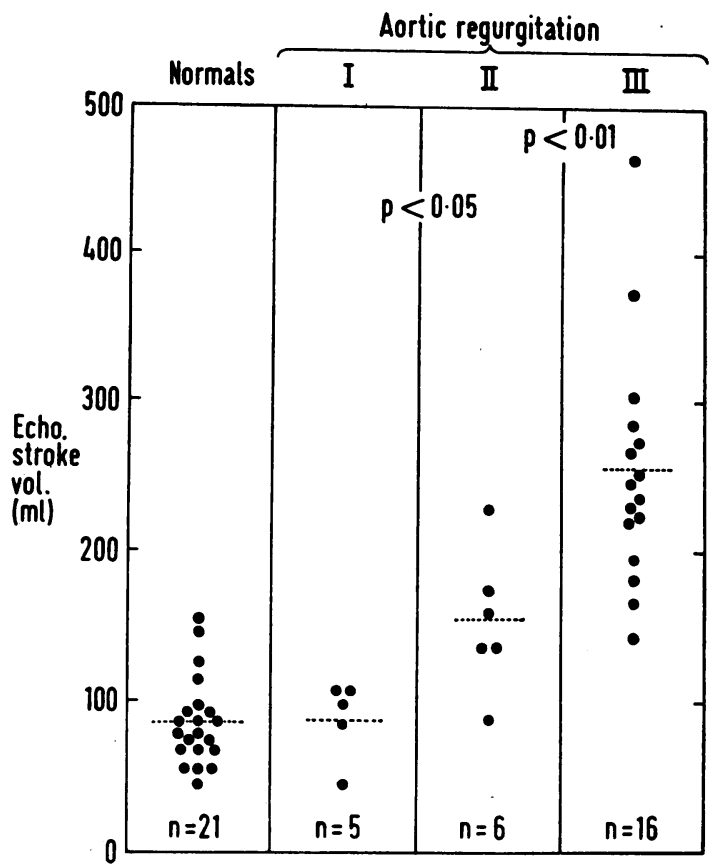

FIG. 4 Total stroke volume in the normal subjects, and in the three grades of severity of aortic regurgitation.

left ventricular diameter but much larger stroke volume. These relations between left ventricular diameter and stroke volume are summarized in the ejection fractions shown in Fig. 7.

The range of ejection fraction in the normal subjects was 0.55 to 0.80 . In the patients with cardiomyopathy and left ventricular failure the range was 0.10 to 0.39 . The patients with aortic regurgitation showed a wider range of values than the normal subjects but only one patient showed an ejection fraction below the normal range. This patient (Case 13)

TABLE 3 Echocardiographic findings in patients with cardiomyopathy and left ventricular failure

\begin{tabular}{|c|c|c|c|c|c|c|c|}
\hline Case No. & $\begin{array}{l}\text { Age }(y r) \text { and } \\
\text { sex }\end{array}$ & $\begin{array}{l}L V \text { diastolic } \\
\text { diameter }(\mathrm{cm})\end{array}$ & $\begin{array}{l}\text { LV systolic } \\
\text { diameter }(\mathrm{cm})\end{array}$ & $\begin{array}{l}\text { Total stroke } \\
\text { volume }(\mathrm{ml})\end{array}$ & Heart rate & $\begin{array}{l}\text { Total LV } \\
\text { output }\end{array}$ & $\begin{array}{l}\text { Ejection } \\
\text { fraction }\end{array}$ \\
\hline I & 5I M & 7.2 & 6.3 & II5 & I 10 & 12.6 & 0.31 \\
\hline 2 & $48 \mathrm{M}$ & 6.7 & 6.1 & 68 & 88 & 6.0 & 0.23 \\
\hline 3 & $57 \mathrm{M}$ & 7.4 & 6.6 & 117 & 76 & 8.9 & 0.29 \\
\hline 4 & $49 \mathrm{M}$ & 6.3 & 5.7 & 67 & 97 & 6.5 & 0.27 \\
\hline 5 & $20 \mathrm{M}$ & 6.6 & 6.4 & 29 & 103 & 3.0 & 0.10 \\
\hline 6 & $57 \mathrm{M}$ & 6.8 & 5.8 & 126 & 57 & 7.1 & 0.39 \\
\hline $\begin{array}{l}\text { Range } \\
\text { Mean }\end{array}$ & & $\begin{array}{l}6.3-7.4 \\
6.8\end{array}$ & $\begin{array}{l}5.7-6.6 \\
6.1\end{array}$ & $87^{29-126}$ & $\begin{array}{l}76-110 \\
88\end{array}$ & $\begin{array}{l}3.0-12.6 \\
7.3\end{array}$ & $\begin{array}{l}0.10-0.39 \\
0.26\end{array}$ \\
\hline
\end{tabular}


with an ejection fraction of 0.44 was a man of 42 with severe aortic regurgitation but very mild breathlessness on exertion. At cardiac catheterization two days previously he had shown a mild increase in left ventricular end-diastolic pressure at I4 $\mathrm{mmHg}(1.9 \mathrm{kPa})$ and his pulmonary wedge

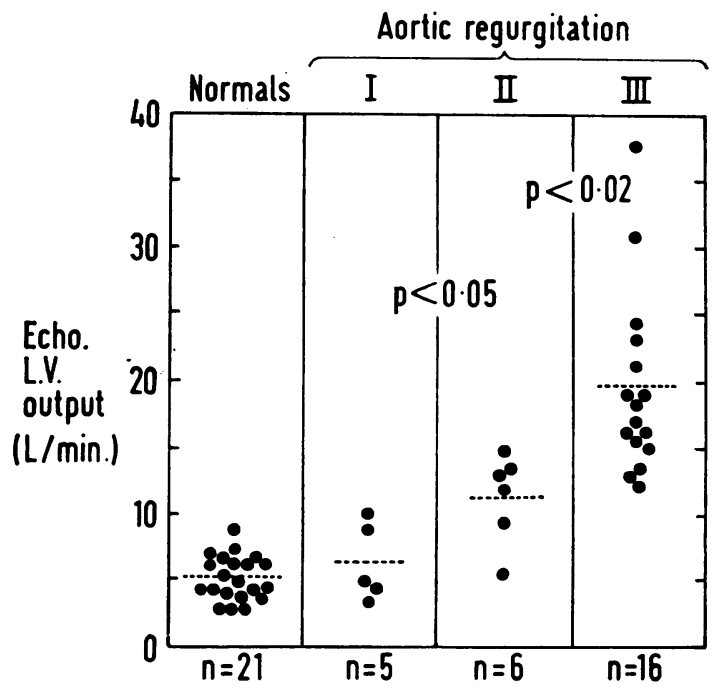

FIG. 5 Total left ventricular output in the normal subjects and in the three grades of severity of aortic regurgitation.

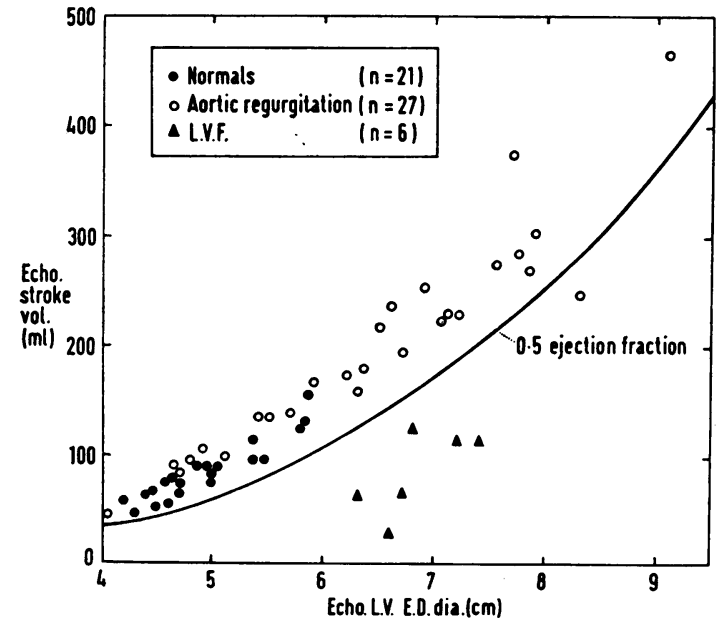

FIG. 6 The relation between left ventricular enddiastolic diameter and estimated stroke volume in the three groups of subjects. The line joins theoretical points having an ejection fraction of 0.5 .

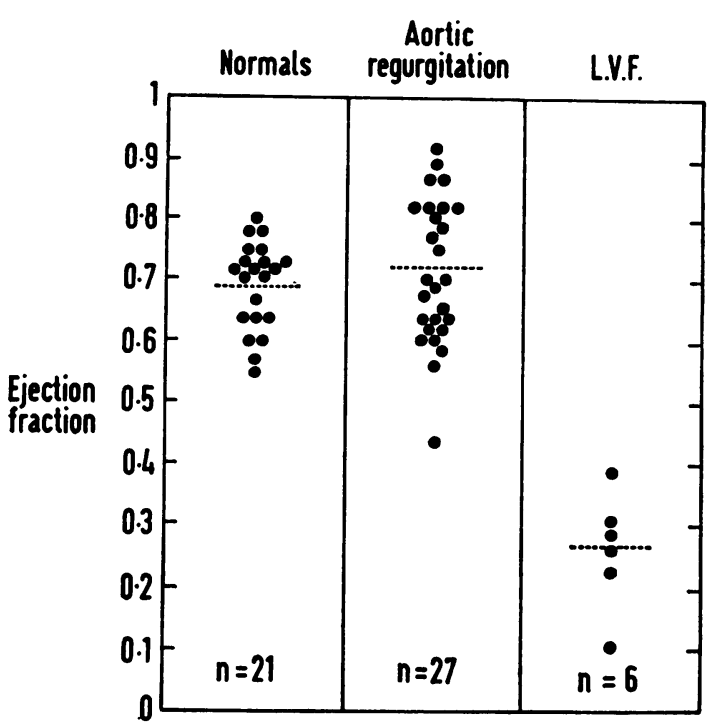

FIG. 7 Ejection fraction in the three groups of subjects.

pressure on exercise rose to $30 \mathrm{mmHg}(4.0 \mathrm{kPa})$. There were 6 other patients (Cases I2, I4, I5, I7, 22, and 23) who had had cardiac catheterization within 4 weeks of the echocardiographic study and had shown left ventricular end-diastolic pressures or pulmonary wedge pressures raised at levels between I8 and $50 \mathrm{mmHg}(2.4$ and $6.7 \mathrm{kPa})$ and none of these patients had an ejection fraction depressed below the normal range. None of the 6 patients who were referred for aortic valve replacement shortly after the echocardiographic study showed a depressed ejection fraction.

\section{Reproducibility study}

The second measurement of left ventricular enddiastolic diameter was within Io per cent of the first measurement in all 22 pairs of recordings, and agreement was within 5 per cent for 20 of the 22 pairs of recordings. The paired measurements of stroke volume agreed within 15 per cent for 18 of the 22 pairs, and for left ventricular output the readings were within 15 per cent for 19 of the 22 pairs.

\section{Postoperative study}

In all 5 patients who were studied at intervals of 13 days to I I weeks after operation, the left ventricular diastolic diameter had decreased to within the normal range (Table 4). In the 4 patients without left bundlebranch block, the total stroke volume and total left 
TABLE 4 Pre- and postoperative findings in 5 patients with aortic regurgitation

\begin{tabular}{|c|c|c|c|c|c|c|c|c|c|c|c|c|c|}
\hline \multirow[t]{2}{*}{$\begin{array}{l}\text { Case } \\
\text { No. }\end{array}$} & \multicolumn{2}{|c|}{$\begin{array}{l}\text { LV diastolic } \\
\text { diameter }(\mathrm{cm})\end{array}$} & \multicolumn{2}{|c|}{$\begin{array}{l}\text { LV systolic } \\
\text { diameter }(\mathrm{cm})\end{array}$} & \multicolumn{2}{|c|}{$\begin{array}{l}\text { Total stroke } \\
\text { volume }(\mathrm{ml})\end{array}$} & \multicolumn{2}{|c|}{ Heart rate } & \multicolumn{2}{|c|}{$\begin{array}{l}\text { Total LV } \\
\text { output }(l / \min )\end{array}$} & \multicolumn{2}{|l|}{$\begin{array}{l}\text { Ejection } \\
\text { fraction }\end{array}$} & \multirow{2}{*}{$\begin{array}{l}\text { Interval } \\
\text { between } \\
\text { operation and } \\
\text { postoperative } \\
\text { study }\end{array}$} \\
\hline & \multicolumn{2}{|c|}{ Pre-op. Post-op } & \multicolumn{2}{|c|}{ Pre-op. Post-op } & \multicolumn{2}{|c|}{ Pre-op. Post-o } & \multicolumn{2}{|c|}{ Pre-op. Post-o } & \multicolumn{4}{|c|}{ Pre-op. Post-op. Pre-op. Post-op. } & \\
\hline 12 & 6.6 & 5.3 & 3.7 & 3.9 & 236 & 93 & 78 & 72 & 18.3 & 6.7 & 0.82 & $0.6 \mathrm{I}$ & 13 days \\
\hline 15 & 5.9 & 4.9 & 3.3 & 2.9 & 167 & 92 & 90 & 62 & 15.0 & 5.7 & 0.82 & 0.78 & Io weeks \\
\hline 17 & 7.2 & 5.0 & 5.2 & 3.4 & 230 & 91 & 73 & 77 & 16.9 & 7.0 & 0.63 & 0.70 & II weeks \\
\hline 28 & 8.0 & 4.9 & 5.1 & 3.7 & 378 & 69 & 62 & 77 & 23.6 & 5.3 & 0.74 & 0.57 & 5 weeks \\
\hline 29 & 6.0 & 5.2 & 4.5 & 3.6 & (LBBB) & & 84 & $8 x$ & (LBBB & & (LBBB) & & 6 weeks \\
\hline
\end{tabular}

LBBB, Left bundle-branch block.

ventricular output had also fallen to within the normal range.

\section{Discussion}

In dominant aortic regurgitation, total stroke volumes of up to $390 \mathrm{ml} / \mathrm{min}$ and left ventricular outputs of up to $28 \mathrm{l} / \mathrm{min}$ have been recorded by quantitative angiography and stroke volumes of up to $4 \mathrm{IO} \mathrm{ml}$ and left ventricular outputs of up to $36 \mathrm{l} / \mathrm{min}$ by dye dilution methods (Miller et al., 1965; Frank et al., 1966). Such greatly increased stroke volumes can be obtained only by an increased diastolic volume. Echocardiography by measuring left ventricular diameter appears to be a particularly suitable method of assessing the increased diastolic size.

The chest radiograph is probably a poor method of accurately assessing left ventricular size in aortic regurgitation. When compared with angiography the chest radiograph has been shown to be a poor predictor of left ventricular size after myocardial infarction (Feild et al., 1974). In our series of patients with aortic regurgitation, left ventricular diameter was significantly larger with increasing clinical severity in the three grades into which the patients were subdivided.

The single beam pulse echocardiographic technique used measures only one diameter of the left ventricle and derivation of left ventricular volume from the single measurement relies on the assumption that the shape of the left ventricle is that of a prolate ellipse. Derivation of stroke volume also assumes symmetrical contraction. All the information obtained regarding left ventricular dimensions is contained in the values recorded from the left ventricular diastolic diameter and systolic diameter, and the only attraction of expressing these values as volumes is to put the information in a familiar and meaningful form, as a unit of contraction of diameter in a large ventricle results in a greater volume change than it does in a small ventricle. It has been suggested that the cube formula for deriving left ventricular volumes from the left ventricular diameter exaggerates the volume in larger ventricles, and Fortuin et al. (197I) used a regression equation instead of a cube formula to obtain left ventricular volume. However, other workers have found that the cube formula remains reasonably accurate over a wide range of left ventricular size (Pombo et al., I97I; ten Cate et al., I974). From the examination of our data for patients with cardiomyopathy and left ventricular failure, it appears likely that the stroke volume and left ventricular outputs are exaggerated in some of these patients though we have no other measurement of output for comparison. However, there is a striking difference in stroke volume between these patients and the patients with aortic regurgitation who have left ventricles of similar size. While accepting that the stroke volumes and left ventricular outputs are approximate, they do show significantly increased values with increasing severity of aortic regurgitation in the three groups. It is noteworthy that the 2 patients (Cases I5 and 23) with severe regurgitation yet high normal or modestly raised values for left ventricular enddiastolic diameter, stroke volume, and total left ventricular output, are the 2 patients with relatively acute aortic regurgitation because of a recent subacute bacterial endocarditis. It is likely that in such patients the severity of the clinical picture is caused by the high left ventricular end-diastolic pressure and left atrial pressure which results from a relatively small volume of blood regurgitating into a chamber which is less compliant than that associated with longstanding regurgitation. This raised left ventricular 
end-diastolic pressure does not imply myocardial failure (Braunwald and Ross, 1963).

Miller et al. (1965), Tyrrell et al. (1970), and Chatterjee et al. (I97I) have shown that the ejection fraction is frequently well maintained even in the face of severe aortic regurgitation. Chatterjee et al. reported that left ventricular end-diastolic pressure, unlike ejection fraction, was a poor index of left ventricular dysfunction. Only one of our patients showed a depressed ejection fraction, but, as indicated above, there was a high proportion of patients in the series who had relatively acute aortic regurgitation in which the symptoms and haemodynamic disturbance may not necessarily reflect myocardial dysfunction.

Our assessment of the value of echocardiography in aortic regurgitation has been limited to a correlation with three grades of severity assessed by other means. To define further the sensitivity of the method, it would be necessary to compare echocardiographic findings with a continuously variable method of assessment of regurgitation such as quantitative angiography.

Our small group of preoperative and postoperative recordings showed that in all 5 patients the left ventricular diameter was reduced to within the normal range, and similar changes in stroke volume and total left ventricular output occurred in those patients in whom these parameters could be estimated. These findings are in accordance with the findings of Kennedy et al. (1968) who reported that in dominant aortic regurgitation the left ventricular end-diastolic volumes and left ventricular stroke volumes decreased towards normal in the absence of postoperative aortic regurgitation.

\section{Conclusions}

The main value of echocardiographic study of the left ventricle in aortic regurgitation is that it offers a more accurate measurement of left ventricular chamber size in diastole than is possible from the plain chest radiograph. This information is of value, as in chronic and severe aortic regurgitation left ventricular size must increase if forward output is to be maintained. Further information may be obtained from the degree of shortening of the left ventricular diameter in systole and this may be conveniently expressed as a volume and an ejection fraction. By detecting a depressed ejection fraction the method may be of diagnostic value in a patient with aortic regurgitation and myocardial failure caused by the regurgitation or some other factor. It is possible that repeated studies in the long term follow-up of patients with aortic regurgitation may give early warning of myocardial failure by detecting an ejection fraction which is falling while still remaining within the normal range.

We thank Dr. F. G. M. Ross and the staff of the Department of Ultrasonics, for allowing us to use the facilities of the department, and for criticism, and Dr. J. Russell Rees and Dr. S. C. Jordan for permitting us to study their patients.

\section{References}

Braunwald, E., and Ross, J., Jr. (1963). Editorial. The ventricular end-diastolic pressure. American fournal of Medicine, 34, 147.

Cate, F. J. ten., Kloster, F. E., van Dorp, W. G., Meester, G. T., and Roelandt, J. (1974). Dimensions and volumes of left atrium and ventricle determined by single beam echocardiography. British Heart fournal, 36, 737.

Chapelle, M., and Mensch, B. (1969). Étude des variations du diamètre ventriculaire gauche chez l'homme par échocardiographie transthoracique. Archives des Maladies $d u$ Coeur et des Vaisseaux, 62, 1505.

Chatterjee, K., Sacoor, M., Sutton, G. C., and Miller, G. A. H. (197r). Assessment of left ventricular function by single plane cineangiographic volume analysis. British Heart fournal, 33, 565 .

Cohn, L. H., Mason, D. T., Ross, J., Jr., Morrow, A. G., and Braunwald, E. (1967). Preoperative assessment of aortic regurgitation in patients with mitral valve disease. American fournal of Cardiology, 19, 177.

Danford, H. G., Danford, D. A., Mielke, J. E., and Peterson, L. F. (1973). Echocardiographic evaluation of the hemodynamic effects of chronic aortic insufficiency with observations on left ventricular performance. Circulation, 48, 253.

Feigenbaum, H., Zaky, A., and Nasser, W. K. (1967). Use of ultrasound to measure left ventricular stroke volume. Circulation, 35, 1092.

Feild, B. J., Russell, R. O., Jr., Moraski, R. E., Soto, B., Hood, W. P., Jr., Burdeshaw, J. A., Smith, M., Maurer, B. J., and Rackley, C. E. (1974). Left ventricular size and function and heart size in the year following myocardial infarction. Circulation, 50, 331.

Fortuin, N. J., Hood, W. P., Sherman, M. E., and Craige, E. (197I). Determination of left ventricular volumes by ultrasound. Circulation, 44, 575.

Frank, M. J., Casanegra, P., Nadimi, M., Migliori, A. J., and Levinson, G. E. (1966). Measurement of aortic regurgitation by upstream sampling with continuous infusion of indicator. Circulation, 33, 545.

Gibson, D. G. (1973). Estimation of left ventricular size by echocardiography. British Heart fournal, 35, 128.

Kennedy, J. W., Twiss, R. D., Blackmon, J. R., and Merendino, K. A. (1968). Hemodynamic studies one year after homograft aortic valve replacement. Circulation, 37 and 38, Suppl. II, I 10.

McDonald, I. G. (1973). Echocardiographic demonstration of abnormal motion of the interventricular septum in left bundle branch block. Circulation, 48, 272.

Miller, G. A. H., Kirklin, J. W., and Swan, H. J. C. (1965). Myocardial function and left ventricular volumes in acquired valvular insufficiency. Circulation, 31, 374. 
Pombo, J. F., Troy, B. L., and Russell, R. O., Jr. (I97I). Left ventricular volumes and ejection fraction by echocardiography. Circulation, 43, 480.

Popp, R. L., and Harrison, D. C. (1970). Ultrasonic cardiac echography for determining stroke volume and valvular regurgitation. Circulation, 41, 493.

Tyrrell, M. J., Ellison, R. C., Hugenholtz, P. G., and Nadas,
A. S. (1970). Correlation of degree of left ventricular volume overload with clinical course in aortic and mitral regurgitation. British Heart fournal, 32, 683.

Requests for reprints to Dr. K. E. Gray, Barnet General Hospital, Wellhouse Lane, Barnet, Herts EN5 3DJ. 